\title{
How Home Contexts of South African University Students Shape their Experiences of Emergency Remote Teaching and Learning
}

\author{
Ansurie Pillay, Martha Khosa, Ayub Sheik, Bridget Campbell, Bheki Mthembu, and Nicholus Nyika \\ University of KwaZulu-Natal, South Africa
}

\begin{abstract}
The shift to Emergency Remote Teaching and Learning (ERTL) in response to the COVID-19 pandemic has necessitated online learning at home for South African (and other) students. Using a critical paradigm, qualitative approach and case study design, this study, underpinned by critical theory, used interviews, voice notes and text messages to generate data to explore how South African university students' home contexts shape their experiences of ERTL. Using thematic analysis, the findings indicated that student learning at home was negatively impacted by poor internet connectivity, home responsibilities, cramped living conditions, lack of safety, and financial and psychosocial stresses. The findings exposed the lived realities of students' home contexts, made more difficult through the pandemic. This study adds to the literature on student adaptation to learning in the pandemic within home contexts characterised by resource poverty and challenging psycho-social conditions.
\end{abstract}

Keywords: Emergency Remote Teaching and Learning, COVID-19, home context, student experience.

\section{Introduction}

The COVID-19 pandemic has not only affected people through illness and death but has impacted the world economy and disrupted social life as we know it. World leaders, guided by the World Health Organisation, have introduced measures to contain the virus, including the shutdown of economic activity and closure of sectors, including education. As the COVID-19 contagion spread throughout the globe, many universities, including South African universities, were forced to move to Emergency Remote Teaching and Learning (ERTL) to maintain the integrity and sustainability of their teaching and learning programmes. ERTL measures, according to Hodges, et al. (2020), involve "the use of remote teaching solutions for instruction that would otherwise be delivered face-to-face or as blended courses and that will return to that format once the emergency has abated" (p.13). In other words, students needed to engage with learning remotely from their home contexts.

Socio-economic conditions under which students live constitute a crucial factor in academic performance. Statistics indicate that approximately half of the population in South Africa lives below the upper-bound poverty line (Statistics South Africa, 2020). For persons living below the poverty line, home contexts are characterized by limited access to water, sanitation and electricity, and extreme conditions of poverty and social ills, none of which are conducive to academic activity. Deprived home contexts in South Africa are characterized by overcrowding, discord amongst family and community members, and high levels of violence and crime, and university students' failure may be attributable to such home contexts (Machika \& Johnson, 2015). Similarly, deprived home contexts might not include online internet access (Czerniewicz et al., 2009). For many students,

Except where otherwise noted, content in this journal is licensed under a Creative Commons Attribution 4.0 International Licence. As an open access journal, articles are free to use with proper attribution. ISSN: 2205-0795 
therefore, university accommodation is important as it guarantees access to a conducive study environment with electricity and internet connectivity. With students working from home in the context of the COVID-19 pandemic, it becomes important to interrogate how the home contexts of South African university students shape their experiences of ERTL.

This study was prompted by a student's text message on a class WhatsApp messaging system (set up for students and lecturers in the class). The student reported that their absence from was because they had no prepaid phone credit available to access the lecture on their cellphone. Some students accused them of being lazy and the student responded by calling-out their privilege and added that the university presumed that all students came from academic-supportive home backgrounds. The researchers of this study, who knew a little about students' home contexts, realised the need to better: understand the students, shape responses in teaching, and enable student success. Thus, this study aimed to answer the research question: How do the home contexts of South African university students shape their experiences of ERTL? In this paper, the literature related to the study is reviewed, the methodology used to conduct the study is outlined, the findings from the data are discussed, and concluding thoughts are shared.

\section{Literature Review}

This thematically arranged literature review, drawn from peer-reviewed publications, media reports and community websites evaluates university students' experiences of learning at home during ERTL within different geographical and socio-economic contexts.

\section{Students' Challenges Navigating ERTL}

With only a 53\% internet penetration rate and amongst the highest data costs in Africa (Chinembiri, 2020), South Africa has a low infrastructural starting point with deep digital divides. This is illustrated by Cleophas (2020), who notes that South Africa's unequal society is manifest in the difference between students with high-end computers and those who do not have enough to eat. The conditions within this unequal society have been exacerbated by the introduction of ERTL in response to the COVID19 pandemic (Czerniewicz et al., 2020). A study by Czerniewicz et al. (2020) in South Africa found that most university students came from schools where they were not introduced to computers, and COVID-19 has added an additional layer to their historical disadvantage.

Rahman's (2020) reflections as a high school student in Australia recognised the need for adjustments regarding student voice and participation during ERTL, as there were more instances of teacher-talk rather than active dialogue and collaborative learning, leading to a limited sense of belonging. Etienne et al. (2020) also reported a diminished sense of belonging in a United Kingdom (UK) study in which students often refrained from asking questions online and attempted to trouble-shoot with peers via WhatsApp groups or blog posts later. This UK study reports that while lecture slides were available, the bullet points provided limited information and were inadequate for learning needs. Where lectures were provided online with audio voiceovers, though, enhanced learning and understanding resulted. In contrast, a study by Aucejo et al. (2020) in the United States (U.S.), found that students wanted more interactive learning, with fewer pre-recorded lectures and slides, opportunities to ask questions, support from lecturers, and assistance with accessing technologies and learning resources. In another survey from the U.S., Daval (2020) found that nearly $64 \%$ of students were grappling with maintaining focus and discipline, and lacking motivation during ERTL. Although $60 \%$ of students were reported to be technically prepared for the paradigm shift towards online education, the remaining students had yet to adapt to the new normal (Daval, 2020).

\section{Students' Experiences of Learning at Home in the Context of ERTL}

A study by Bhamani et al. (2020) found the transition to online learning in Pakistan has been marked by trial and error and uncertainty for students who needed to compete for access to single home computers. Similarly, a study by Soria et al. (2020), with first-generation students in the US, found that students were less able to meet during scheduled virtual class times than other students. Robinson (2020) points out that students are learning from home under tremendous personal strain and anxiety due to the fear of infection, suitable study areas, and anxiety over adequate internet access. These findings are corroborated by Kapasia et al. (2020) in West Bengal, where poor internet connectivity, lack of conducive learning spaces at home, and economic stresses made learning challenging. A further dimension emanated from Cohen et al.'s (2020) U.S. study, which found that $17 \%$ of students were living with and providing childcare and/or schooling assistance for siblings and/or cousins in 
their households, although this varied by gender. Complicating the home dynamic was the aspect of safety where findings from Soria et al. (2020) suggest that first-generation students were less likely to live in safe households free from physical, emotional or substance-related abuse.

Financial constraints also manifest within the context of learning at home during the pandemic. Soria et al. (2020) found that U.S. students included in their study experienced food and housing insecurities, family members lost wages, students lost onor off-campus employment, and living and technology expenses increased. Similarly, Aucejo et al. (2020) noted that 40\% of a sample of U.S. students had lost jobs, internships, or job offers, and 13\% had delayed graduation. similarly, Hofmeyr's (2018) South African study found that the greatest setback to learning at home was the precarious economic conditions of families marked by increased unemployment and the prioritising of scarce material resources for survival.

Aligned to the stresses of financial constraints, many students experienced mental health challenges. The European study by Weissova et al. (2020) found that students' mental health was negatively impacted by the uncertainty and anxiety they were facing in their everyday lives following the onset of the pandemic. Soria et al. (2020) discovered that first-generation U.S. students experienced higher rates of mental health disorders compared to their continuing-generation peers with most students in the study reporting a generalized anxiety disorder due to the sudden changes brought about by COVID-19, and with some students reportedly living in spaces where their identities were not respected.

Of interest are the findings from the study by Aucejo et al. (2020) that effects of the pandemic are heterogeneous. The findings, determined by existing socio-economic divides, indicate that a quarter of higher-socioeconomically located students increased their study time by more than four hours per week during COVID-19, while another quarter of lower-socio-economically located students decreased their study time by more than five hours per week.

The research on student experiences of ERTL during the COVID-19 pandemic suggests that research pertaining to students mired in resource poverty and economic precarity in African contexts has not yet been comprehensively addressed. This gap served as impetus for the study reported in this paper.

\section{Methodology}

This study is underpinned by critical theory which attempts to understand conflict and oppression and appraise the unequal structures and relationships within communities (Gruenewald, 2003). This theory centres experiences and histories (Carspecken, 1996) and the issues of struggle and hegemony underpin analyses (Abrahams, 2004). The theory locates situations and people within wider social and political contexts, unpacks the commodity exchange economy, unmasks hegemonic ideologies, and considers the extent to which agency is exercised (Brookfield, 2005). Gramsci (1971) notes that hegemonic ideologies are assimilated through social and cultural constructions via schooling and family, among other institutions. In this study, critical theory underpins the understanding of how home contexts of South African university students shape their experiences of ERTL.

With an underpinning of critical theory, the study used a critical paradigm, qualitative approach, and case study design. A critical paradigm focuses on issues of inequality and power (Guba \& Lincoln, 1988). This approach was considered suitable for the study because of its emphasis on how inequality of resources privileged some students and disadvantaged others. A single case study design was used to enable the provision of a comprehensive portrayal of individual units (home contexts) of participants (South African university students) within a certain context (ERTL in the pandemic) so as to allow understanding of the issues being studied (experiences of ERTL) (Duff \& Anderson, 2015). Each of these choices enabled answers to the research question: How do the home contexts of South African university students shape their experiences of ERTL?

Gatekeeper permission and ethical clearance were obtained from the university in which the study was located, and a class of exit-level students were invited to participate. Seven students (of a class of 70 students) volunteered to participate and were asked to sign informed consent forms. The fact that participants were known to one researcher who taught them was identified as an ethical issue and thus the participants were guaranteed anonymity and confidentiality and were assured that they could withdraw their participation at any time without supplying reasons and with no consequences to themselves. It was explained to the participants that when information was shared with the other five researchers, they would be referred to by numbers only. The participants self-identified as three African males, three African females, and one Indian female, aged between 26 and 28 
years. During term time, six students resided at university residences, and one resided at her home. Outside of term time, of the seven participants, five lived in minimally resourced urban areas surrounding the city, Durban, and two resided in rural areas characterised by resource poverty.

Qualitative data were collected through individual semi-structured interviews conducted via the Zoom video communication system. Semi-structured interviews provided opportunities for the participants to share their ideas and experiences in response to open-ended questions. The interviews, recorded with participants' permission, were in-depth and conversational with probing follow-up questions. Notes were taken during interviews to supplement data gathered through the audio recordings and the interviewer sent follow-up questions via voice notes on the WhatsApp messaging system. The participants responded to the follow-up questions through narratives on WhatsApp or email and were invited to expand on what they had said or written and all participants took up these invitations. Their additional post-interview data helped triangulate the interview data.

All Zoom interviews and WhatsApp voice messages were transcribed verbatim, and, together with written responses, were analysed using thematic analysis, which involves looking closely through all the data to find recurring patterns of meaning (Braun \& Clarke, 2006). Thematic analysis was considered useful for this study because of its flexibility and ease of use when analysing qualitative data, and in line with Braun and Clark (2006), was carried out in six stages. In the first stage, each of the six researchers worked independently to become acquainted with the data. In the second stage, the individual coding of data took place followed by the third stage when themes were identified. In the fourth stage, the six researchers shared their themes, which were then reviewed. In the fifth stage, themes were defined and named collectively, and in the final stage, the written analysis was done by one researcher.

Trustworthiness was ensured using Lincoln and Guba's (1985) criteria which included credibility, dependability, confirmability, and transferability. Credibility was enabled through prolonged engagement with participants, methods triangulation, using three methods of data generation (interviews, voice notes and narratives), and investigator triangulation, where the six researchers embarked on the data analysis individually before coming together weekly to share themes. Dependability was demonstrated by carefully recording and transcribing interviews verbatim and by keeping track of the coding, re-coding, and changing of researchers' decisions. Confirmability was ensured by providing a detailed description of methodological choices and the reasons for such. Transferability, which focusses on the applicability of the findings and conclusions to other higher education institutions, might be a limitation of the study as the context being described might not apply to all contexts. However, the context shares affinities with conditions characterized by resource poverty of students, now exacerbated by the pandemic. In addition to the possible limitation of transferability, the researchers recognised that the sample size was small (increasing the size serves as a possibility for future research), and thus aimed to generate as much data as possible to fully understand the phenomenon under study. Generating large amounts of data meant that analysis was timeconsuming but the motivation for the research moved the analysis and discussion of findings forward.

\section{Discussion of Findings}

The analysis of the data revealed the following themes: Students' challenges of ERTL; Students' responsibilities in the home within the context of ERTL; Space, safety, and stresses in the home against a backdrop of ERTL.

\section{Students' Challenges of ERTL}

Findings suggest that the participating students from poor economic backgrounds believed the university could have done better in preparing them for ERTL. The following sentiment expressed by Student 6, an African male from a rural home context, aptly sums this theme up, noting, "The institution assumed that we are of the same background or we are all privileged."

The sentiment from Student 6 echoes those of others who found themselves helpless within their home contexts without any recourse to assistance as they tried to make sense of the unfamiliar ERTL. Student 7, an African male from an under-resourced urban home context, shared that, "I don't know how to use my laptop properly" for ERTL. Student 6, too, noted that "it's challenging because for some of us, this is new. We had to adapt, but we're not familiar with it. And we were not given any tutorials on it." The student reflects an understanding that the university did not realise that students do not come from the same backgrounds and electronic gadget use is not necessarily a norm, as borne out by the study by Czerniewicz et al. (2020). Both students found themselves being forced by circumstances to adapt and embrace a mode of learning with which they are not 
familiar and for which they feel they have not been adequately prepared. Using a critical lens, it would seem that these students arguably find themselves excluded, marginalised, and alienated because of their circumstances of inequality which privileged some and disadvantaged others (Kincheloe \& McLaren, 1994).

Living in areas with regular power failures or with poor network connectivity meant that some students could not access ERTL sessions. Student 4, an African female student living in an under-resourced urban home context, noted not having electricity "for more than three days" at a time and Student 1, an African female student living in a rural area, had to deal with a "poor signal" which meant she could not "access material or even log on to Moodle" (Moodle is the Learning Management System used by the university). However, both students did not passively accept the circumstances in which they found themselves. Student 4 "tried emailing the municipality but did not get any help" and Student 1 noted that she would "go outside the house and move around the yard" to find a signal, "even on cold days, you go to places where the connection is better." Drawing on Brookfield's (2005) critical theory framework on learning, it would seem that both students exercised their agency to help themselves, despite difficult learning situations. However, the situations that the two students found themselves equally highlights how the inequality of resources privilege some and disadvantage others (Kincheloe \& McLaren, 1994).

Problems such as lack of or poor network connectivity are beyond the control of the university. However, the students identified the university's approach in dealing with their needs as failing to embrace an emancipatory position. The students' statements reflect their views that the university based its decisions on a flawed assumption that sought to perpetuate the narrative of a student body that is both homogeneous and elite when, as Cleophas' (2020) study shows, the opposite is true. By so doing, the university failed to take into consideration the unequal structures and relationships within communities (Gruenewald, 2003) and the realities of students' lives.

\section{Students' Responsibilities in the Home Within the Context of ERTL}

As students navigated their remote online learning experiences in the COVID-19 pandemic, they did it within contexts of responsibilities in the home. These included caring for the family and doing home chores. Students 1,4 and 7 were expected to care for family members. Student 1 was expected to look after her diabetic grandmother and one year-old nephew. She stated that she needed to "ensure that [her grandmother] has taken her pills in the morning and I have to inject her twice every day. I have to do it. It's my duty." She also had to care for her nephew and noted, "You cannot leave him alone. When I look after him, I can't do any work. I'm trying, but it's hard." Like Student 1, Student 4 lived with an extended family of a brother, 90 year old blind grandmother, aunt, and her aunt's grandchild. When Student 4 went home from her university residence, she was put in charge of her grandmother and the child. She stressed that "they understand that I'm supposed to be studying, but there are things to do." Student 4 was conflicted between priorities of commitment to her family and investing in her academic endeavour. She faced demands from both sectors and, unless she was able to balance the demands expected of her, she could face failure in one or both parts of her life. Like Students 1 and 4, Student 7 was expected to take care of his sister's four yearold toddler. While his sister was at work, he had to "care for the child, make her food, wash her." He noted that "the only time that I have to myself is when she is asleep." Having childcare responsibilities could imply restricted engagement with his learning. While expressing a sense of frustration with the demands on his time, he recognized some personal time when the child was asleep.

The tension between family responsibilities and academic demands of the three students must be understood within a social and economic context that demanded non-negotiable involvement in fulfilling responsibilities. They recognized that they needed time and space to succeed academically, but this recognition was located within the interconnectedness and struggles among their educational, societal, and cultural responsibilities (Abrahams, 2004). The conflict of responsibilities reflected how a social structure shaped experiences (Kincheloe \& McLaren, 1994) and how those experiences could work against the students' academic success. From a critical perspective, the situations within which the students found themselves needed to be understood within the social contexts in which they lived and worked (Brookfield, 2005), where priorities might not give precedence to academic ones.

While students 1, 4 and 7 pointed to caring for family members, there was also a strong focus from the participants on the many chores they needed to complete each day in their homes. Student 5, an African female living in an under-resourced urban area. stated that "when there are [ERTL] lectures at eight in the morning, I wake up earlier to clean the house so I can focus on what the lecturer says and get time to study and go through my notes." In many ways, Student 5 demonstrated agency in doing what 
she had to do to achieve success. Student 3, an Indian female living in an under-resourced urban area, referred to the chores in relation to the others in the home and said, "I clean the house, making sure that when they get back, they have less to do. In the afternoon, I cook so that when they come home from work tired, they should not be overworked whilst I am home." She recognized that her family had gone to work, and she was at home, demonstrating a belief that she should be doing the house chores as the only one at home. She did not reflect an anti-deficit mindset and while knowing what she needed (the time and space for studying to achieve success), she was also aware of what she had (home and family) (Mejia, et al., 2018).

Student 6, an African male living in a rural farm area, offered a different responsibility in his home context. He noted his responsibility to his chores by reflecting that he could not "do things as per my schedule" and would need to adapt his schedule, as required. He gave an example of being told that he "had to go and inject the cows." He noted that plans could change based on the contextual needs of a farm life, and he reflected his understanding that his study schedule did not take precedence over the demands of the farm. He shared, "It's hard work, like you can't imagine", pointing to the strenuous demands of the work, but also possibly implying that the researcher did not have an understanding of such work. In addition to engaging in farm activities, he indicated his involvement with home chores. He stated that his parents expected the seven children to perform home chores and said, "I'll clean the house, then do my work." Student 6 also alluded to his parents not understanding the demands of ERTL. He noted that his parents:

... will ask you to do something, and you say, I have a Zoom meeting in ten minutes. They think you are dodging chores. I see that reaction on their faces. Sometimes, I'm even scared to tell them I have a meeting. My mum understands but not my father.

What Student 6 revealed was a home context where chores were expected of the student, and these chores needed to be done within the time frames and expectations of the parents. The idea of Zoom meetings was understood by the student within a context of fear and being "scared". Such a home environment might not be optimal for effective teaching and learning. While his mother appeared to understand the need to attend meetings, his father, who ran a farm and realised the demands of running it, possibly recognized another helping hand, not a student sitting in front of a computer. His father worked within a specific social context embedded within a commodity exchange economy (Brookfield, 2005). While the power exercised by the father might appear to be unjust, the father recognized that an extra hand was an economical advantage that could not be ignored.

Home chores were also understood in terms of gender roles. For example, Student 1 noted that she was "the only girl and so I am left with house duties", Student 6 pointed out that "as boys, we are expected to take part in whatever is done at home", and Student 7 explained that "because I am a boy, I have to clean the yard". The findings are in line with those of Cohen et al. (2020) who found that students' home responsibilities varied according to gender. Despite the challenges of mediating home contexts and ERTL, the gender role imperatives added an additional burden. In the main, the participants reproduced, in most instances, the home as a gendered space, and the hegemonic ideas about gender were learned and lived within the social practices in the home context, highlighting Gramsci's (1971) contention that hegemonic practices are allowed to flourish through social constructions such as family, among others.

Despite the challenges posed by juggling home responsibilities and ERTL, students did not always present the situation negatively. For example, Student 1 had worked out that doing her university work was "better during the night" and noted that "some days are better than others". She had identified her learning within the context of her home responsibilities and appeared to accept that her learning would progress more successfully at certain times. The student embraced an anti-deficit framework (Mejia, et al., 2018) by focusing on what she had to do to succeed. The findings reflect that while family care and home chores do impinge on students' abilities to engage with their academic pursuits, the students equally recognized their obligations to the persons with whom they lived and they tried to balance both demands. The findings indicate that lecturers need to understand the competing demands placed on students and implement measures to support students in contexts that might demand more than academic commitment.

\section{Space, Safety, and Stresses in the Home Against a Backdrop of ERTL}

The data showed that students engaged with ERTL within a context of a pandemic and against factors of inequality that limit success. These factors have been broadly categorised as space, safety, and stresses. 
In terms of space, the participants pointed out the lack of space available to engage with ERTL. Student 7 noted that he did not have his own room, but "shared with my brother so there is little privacy. There's no specific place to study. I study in the dining room, sitting room, or take a chair and sit at my bed." He noted that there are "many interruptions." Similarly, Student 6 reflected a lack of "personal space at home." Like Student 7, he shared a room with his brothers and "can't lock the door" in case someone needs to use the room. While there is "an outside building where I can go if I have to do my work, I'm going to be questioned, why are you sitting there?" Student 6 also needed to contend with neighbours who "play really loud music" in the afternoon. He noted that "the music affects my concentration especially since it's already so hard to stop thinking about everything that's going on in my life." For that reason, he was able to attend the morning lectures but struggled to concentrate during the afternoon lectures. Both Students 6 and 7 realised the effect of the lack of resources available to them when studying at home. Their external social realities were not in harmony with their endeavours towards academic success. In addition, the use of ERTL during the pandemic presented a disconnect between a situated pedagogy which did not link the curriculum to the realities of students' lives. Like the study by Kapasia et al. (2020), this study has identified the strain felt by students when engaging in ERTL in the home context because of a lack of suitable spaces in which to work.

A glaring reality of the students in the study was the issue of safety, or lack thereof. Student 6 reflected on a fight with a younger sibling and noted, "He is young. I was disciplining him for doing wrong and he hit me back. When I see him, it reminds me of what happened." What Student 6 revealed was that he used violence but was unhappy about violence being returned. Going beyond sibling rivalry, Student 3 noted the emotional effects of living in "an abusive home" with a father who "abuses my mum physically". She explained that:

campus was my get away from it all. Speaking to my friends helped. It affects me psychologically and emotionally. I just want to get my degree so mum and I can start afresh. I'm always caught up in the arguments

Student 3 recognised the physical and emotional safety net of being on campus. While the student lived the stresses of her life at home, she understood the conflict and envisioned how she would bring about change. Her qualification as a teacher could lead to not just her freedom from abuse, but that of her mother as well. She demonstrated agency in knowing that she could leave the conflict, oppression and unequal relationships (Gruenewald, 2003) present in her home. Student 3's experiences is a reminder to all higher education stakeholders to recognise the significance of students obtaining a degree and to realise that some students might be fighting against tremendous odds to obtain it.

With Student 2, an African male living in an under-resourced urban area, the lack of safety was both physical and emotional. He shared:

I was stabbed and I woke up in hospital. I managed to recover, but I'm stressed emotionally. I can't concentrate. I saw myself as a tough person, but I'm not coping. I talked with my family. They encouraged me. They told me to stand tall, focus, and build myself. I'm not the same person. We live in a very harsh world. A person stabs you because they're enemies with your family. I'll be at ease once they're locked up in jail. They're currently going through the court system, and I'm trying to find a good lawyer to represent me.

Student 2 presented a lived experience of pain and injustice. He recognised the role of his family history and the role of their support to him. His experience in his home context affected his learning and ability to concentrate, and he was dealing with issues beyond that of a typical student. His experiences are glaringly underpinned by the social, emotional, and intellectual realities in his life. However, he has refused to succumb to his insecurities or powerlessness, and instead has focussed on how to move forward. While the Soria et al. (2020) study revealed a lack of safety within the home, Student 2's experiences show how dangers from outside the home have compromised his physical and emotional stability. His experiences highlight conflict, oppression and unequal relationships in communities (Gruenewald, 2003).

Another challenge that existed in the lives of the participating students was financial insecurity. Student 3 noted her father's "gambling addiction" and the potential loss of her own part-time job. She highlighted that "they're speaking of retrenchments. Praying that isn't the case because sometimes I have to run the household. Learning in an environment like this isn't easy. It's difficult to concentrate." Student 5 noted that, "My dad got a letter that his salary was being cut. That's so stressful because he pays my fees. I work part time. Because of the lockdown, the store was closed. It's difficult." The students recognised the power of economic forces in their lives and that their experiences were underpinned by their economic realities. While the Hoffmeyr (2018) study in South Africa reflected how the financial situation in homes decided what needed to be prioritised for 
survival, the lockdown brought on by the 2019 pandemic resulted in job losses and/or salary cuts and further exacerbated negative situations already present in the home and learning environments. While the loss of jobs has been a feature of the pandemic lockdown, as seen in the study by Aucejo et al. (2020), such losses to the students highlight how ideologies and discourses of the economy and education interact to construct their social systems (Kincheloe \& McLaren, 1994). While academic imperatives for student success need to be upheld, it is equally humane to acknowledge and address the issues of poverty and deprivation.

Students' social systems were also impacted by various other stresses in their lives. Two participating students lost family members - a mother and a sister, family members became sick, students could not visit their family members who served as support structures, and a student with an ongoing mental illness found being at home difficult to navigate. Student 5 was able to access her counsellor when at university but could not talk to anyone at home. Talking about her mental illness, she shared, "I can't even feel sick in my own home because I fear being judged." She noted that when at her campus residence, she could have her privacy in her room but that privacy was not possible at home. She also noted that "at home, there is a constant worry about money, there are no jobs, times are tough."

It is clear that death and sickness, a feature of the pandemic, played a role in the students' lives. While illnesses, whether physical or mental, require appropriate treatments, navigating such illnesses within confined home spaces, anxieties around the lack of jobs and money, and persons who do not know how to manage such illnesses, make the experiences worse. Student 5 also stated that "I wish lecturers [would] learn about mental issues. I think it would make them more accommodating of students battling them. Everyone is fighting a fight - I am not the only one who is going through this." Student 5's experiences reflected where she saw power (her family, her lecturers) and the injustices she faced from both. Student 5 understood the help she could access, through counselling, but she challenged lecturers to further empower themselves so that they might understand and help others. Confirming this indication from the present study, the study by Weissova et al. (2020) found that students' mental health was negatively affected by the uncertainty and anxiety they faced in their lives. However, where the present study differs is in the context where mental illness issues combine with financial anxieties, exacerbating the student's apprehensions.

\section{Concluding Thoughts}

Overall, the study recognised three main findings. Firstly, the students' experiences reflected that students are not homogenous and many are not well-resourced. Instituting a one-size-fits-all approach favours students who have resources and seriously disadvantages those who experience resource limitations. Secondly, the students were trying to engage with ERTL within the context of responsibilities in the home. Such responsibilities included care for children and the elderly and home chores, many of which were gendered. Home responsibilities competed with educational demands and the balance between the two were not always equitable. Thirdly, the students' educational endeavours were located in home contexts that lacked resources, including space to work, and in home contexts that experienced domestic abuse and financial insecurity.

These findings require university stakeholders to gain greater awareness of students' realities of the limitations of lived spaces beyond the university and necessitate a rethinking of pedagogies within an ERTL experience during a pandemic and beyond. It becomes clear that students' experiences of ERTL were shaped by their social, emotional and intellectual realities. Further, such realities were located within the experiences of illness and deaths brought about by the COVID-19 pandemic. The findings remind lecturers to recognise that while the academic project continues, it does so within the dynamics and complexities played out in students' homes.

The participating students' experiences highlighted the importance of lecturers being empowered to understand the complexities of the student body, and design instructions and interactions that inspire hope and change in students who often feel marginalised by their inequitable educational, and other, structures and relationships. Students, no matter their contexts and resources, need to be given opportunities and spaces to voice their concerns and share their lived realities as using a onesize-fits-all solution to students' challenges could prove counter-productive. To enable student success, higher education, in all contexts, has to recognise both the varying capital with which students arrive and the realities of students living and studying in often challenging circumstances, and adapt practices to meet academic imperatives while recognising the realities of students' lives. 
This qualitative case study, underpinned by a critical paradigm, adds to the body of knowledge about students' experiences of ERTL during the COVID-19 pandemic and provides an important insight into student success (or lack thereof) within contexts of economic precarity, alienation, failure, and frustration. The pandemic, and the consequences thereof, have exacerbated already burdened home contexts and, in turn, impaired successful learning within such contexts. While the study acknowledges the limitations of using a small sample of students, the qualitative approach was appropriate to elicit participants' rich stories, in their own words, of their lived experiences within the context of ERTL in home contexts during a pandemic.

While this study was located within the context of ERTL during a pandemic, all higher education stakeholders need to grapple in a fair and compassionate way with questions of how to ensure that higher education does not continue with a business-asusual ethos, while hoping for success. The researchers of this study affirm their contention that all higher education stakeholders need to better understand students being taught, shape better responses in the teaching and learning endeavour, and drive humane processes towards student success. 


\section{References}

Abrahams, F. (2004). Application of critical theory to a sixth grade general music class. Visions of Research in Music Education, 4.

Aucejo, E. M., French, J., Ugalde Araya, M. P., \& Zafar, B. (2020). The impact of COVID-19 on student experiences and expectations: Evidence from a survey. Journal of Public Economics, 191. https://doi.org/10.1016/j.jpubeco.2020.104271

Bhamani, S., Areeba, Z. M., Vardah, B., Nasreen, A., Sidra, K., \& Dawood, A. (2020). Home learning in times of COVID: Experiences of parents. Journal of Education and Educational Development, 7(1), 9-26. http://dx.doi.org/10.22555/joeed.v7i1.3260

Braun, V. and Clarke, V. (2006) Using thematic analysis in psychology. Qualitative Research in Psychology, 3 (2). $77-101$. https://doi.org/10.1191/1478088706qp063oa

Brookfield, S. D. (2005). The Power of critical theory for adult learning and teaching. Open University Press.

Carspecken, P. F. (1996). Critical Ethnography in Educational Research: A Theoretical and Practical Guide. Routledge.

Chinembiri, T. (2020). Mobile data pricing policy brief. Research ICT Africa. https://researchictafrica.net/

Cleophas, F. (2020, August 6). Covid-19 pandemic highlights challenges of online teaching and learning. Mail \& Guardian. https://mg.co.za/education/2020-08-06-covid-19-pandemic-highlights-challenges-of-online-teaching-and-learning/

Cohen, A. K., Hoyt, L. T., \& Dull, B. (2020). A descriptive study of COVID-19-related experiences and perspectives of a national sample of college students in Spring 2020. The Journal of Adolescent Health: Official Publication of the Society for Adolescent Medicine, 67(3), 369-375. https://dx.doi.org/10.1016\%2Fj.jadohealth.2020.06.009

Czerniewicz, L., Williams, K., Brown, C. (2009). Students make a plan: Understanding student agency in constraining conditions. ALT-J, Research in Learning Technology, 17(2), 75-88.

Czerniewicz, L., Agherdien N., Badenhorst J., Belluigi D., Chambers T., Chili M., de Villiers M. Felix A., Gachago D., Gokhale C., Ivala E., Kramm N., Madiba M., Mistri G., Mgqwashu E., Pallitt N., Prinsloo P., Solomon K., Strydom S., Swanepoel M., Waghid F., \& Wissing G. (2020). A wake-up call: Equity, inequality and Covid-19 emergency remote teaching and learning. Postdigital Science and Education, 2:946-967. https://doi.org/10.1007/s42438-020-00187-4

Daval, K. (2020). Helping students stay focused while remote learning. University Business.

https://universitybusiness.com/helping-students-stay-focused-while-remote-learning/

Duff, P., \& Anderson, T. (2015). Case study research. In J. D. Brown \& C. Coombe (Eds.), The Cambridge Guide to Language Research. Cambridge University Press.

Etienne, C. F., Fitzgerald, J., Almeida, G., Birmingham, M. E., Brana, M., Bascolo, E., \& Pescetto, C. (2020). COVID-19: Transformative actions for more equitable, resilient, sustainable societies and health systems in the Americas. $B M J$ Global Health, 5(8). http://dx.doi.org/10.1136/bmjgh-2020-003509

Gramsci, A. (1971). Selections from the prison notebooks of Antonio Gramsci. International Publishers.

Gruenewald, D. A. (2003). The best of both worlds: A critical pedagogy of place. Educational Researcher, 32(4), 3-12. https://doi.org/10.3102\%2F0013189X032004003

Guba, E.G. \& Lincoln. Y.S. (1988). Do inquiry paradigms imply inquiry methodologies? In D.M. Fetterman. (Ed.). Qualitative approaches to evaluation in education: The silent scientific revolution. (p. 89-115). Praeger

Hodges, C., Moore, S., Lockee, B., Trust, T., \& Bond, A., (2020). The difference between emergency remote teaching and online learning. Educause Review. https://er.educause.edu/articles/2020/3/the-difference-between-emergency-remoteteaching.

Hoffmeyr. H. (2020). Home background and schooling outcomes in South Africa: Insights from the National Income Dynamics Study. Stellenbosch Economic Working Papers. https://ideas.repec.org/p/sza/wpaper/wpapers294.html

Kapasia, N., Paul, P., Roy, A., Saha, J., Zaveri, A., Mallick, R., Chouhan, P. (2020). Impact of lockdown on learning status of undergraduate and postgraduate students during covid-19 pandemic in west Bengal, India. Children and Youth Services Review, 116. https://doi.org/10.1016/j.childyouth.2020.105194

Kincheloe, J. L., \& McLaren, P. L. (1994). Rethinking critical theory and qualitative research. In N. K. Denzin \& Y. S. Lincoln (Eds.), Handbook of qualitative research (p. 138-157). Sage Publications.

Lincoln, Y.S., \& Guba, E.G. (1985). Naturalistic inquiry. Sage Publications.

Machika, P., \& Johnson, B. (2015). Postgraduate students' experience of poverty and academic success. South African Journal of Higher Education, 29(6), 167-181. https://journals.co.za/journal/high

Mejia, J. A., Revelo, R. A., Villanueva, I., \& Mejia, J. (2018). Critical theoretical frameworks in engineering education: An anti-deficit and liberative approach. Education Sciences, 8(4), 158. doi.org/10.3390/educsci8040158.

Rahman, A. (2020) Harnessing flexibility and freedom: Reflections on remote learning during the COVID-19 pandemic Connect, 243, 23-24. https://research.acer.edu.au/connect/

Robinson, K. (2020). A global reset of education. Prospects, 49, 7-9. https://doi.org/10.1007/s11125-020-09493-y

Soria, K. M., Horgos, B., Chirikov, I., \& Jones-White, D. (2020). First-generation students' experiences during the COVID19 pandemic. UC Berkeley: Center for Studies in Higher Education. https://escholarship.org/uc/item/19d5c0ht

Statistics South Africa. (2020). Poverty and Inequality. http://www.statssa.gov.za/?p=12075. 
Weissova, L., Marinoni, G., \& Leite, J. R. (2020) Students: The missing perspective on the COVID experience. University World News. https://www.universityworldnews.com/post.php?story=20200918141718595.

\section{Please cite this article as:}

Pillay, A., Khosa, M., Sheik, A., Campbell, B., Mthembu, B., \& Nyika, N. (2021). How home contexts of South African university students shape their experiences of emergency remote teaching and learning. Student Success, 12(3), 37-47. https://doi.org/10.5204/ssj.1779

This article has been accepted for publication in Student Success. Please see the Editorial Policies under the 'About' section of the Journal website for further information.

(c) (i) Except where otherwise noted, content in this journal is licensed under a Creative Commons Attribution 4.0 International Licence. As an open access journal, articles are free to use with proper attribution. ISSN: 2205-0795 